\title{
Visual Semiotics of the Spaces We Inhabit: Preface
}

\author{
Sarah Marusek
}

Published online: 14 August 2013

(C) Springer Science+Business Media Dordrecht 2013

In our everyday lives, we occupy a variety of places that, upon first consideration, do not seem either legal or political. Upon closer examination, the spaces where we live may reveal a uniquely visual semiotics of place, a semiotic system that generates meaning and contestation through structure, signage, and symbolism. As sites of power. these places can be urban, rural, or simply in between. The ways in which power manifests itself here is as law, legality, governance. Visual representations of meaning in our quotidian terrain of habitation constitute our relationships and they govern who we are and how we understand our place in the world. The visual engagement with the semiotic construction of who we are as individuals, as a collective, and the presence of both within different communities is visibly marked by the banal as well as by the overtly distinctive. In the routine places of our lives, identities fostered by rules and structures challenge us to reconsider how we conceptualize ourselves, each other, the state, and the spectrum of community therein. In this volume, cultural themes of consumption, normativity, deviance, identity, and governmentality contribute to this visually semiotic relationship shaping our understandings of law, power, and place. An impressive array of images, spaces, and notions of law lays the backdrop to this collection of scholarship critically engaged with everyday objects, uses, and understandings.

Our world comes alive through images. What we see and how we see semiotically constructs our reality and contributes to a constitutive approach to law in which representation and image signify power, resistance, and the mundane. Images, spaces, and law work in conjunction with one another to sculpt our everyday lives. Through images, semiotic representations signify our world. Constructions of spatiality give meaning to how and where we live and spatiality constitutes our notions of what is public, what is less so, and what is not. Landscapes can be outside, in our homes, in the air, on our bodies. A constitutive

S. Marusek (ه)

University of Hawai ‘i, Hilo, HI, USA

e-mail: skmarusek@gmail.com 
approach to law involves semiotics through things and actions that we confront in everyday Western society. It also embraces the everyday contestation of jurisprudence involving a visual construction and digestion of legality. Meanings of law transpire through visual symbols, cues, and other modes of semiotic communication. Representations of power through constructions of governmentality, social discipline, and manifestations of the state engender norms, normativity, and a sense of normalcy that is challenged and resisted. Legal and social culture affects our understandings of justice, fairness, and order.

As the guest editor of this volume and the author of the final article, I consider the ways in which law expects us to react when driving through the yellow American traffic light. The state is interestingly silent on whether or not to always brake or always accelerate; instead the law seems to affirm the individual and contextualized judgment of the driver. I articulate this type of legalized common sense as the "semiotics of context-bound decision-making" that characterizes a notion of visual jurisprudence. In terms of the yellow light, the norm then becomes one of automaticity exercised as legal discretion by the driver in a fleeting moment.

In his work considering the ramifications of norms on the semiotics of everyday life, Goren Sonesson explores social norms insofar as norms can be understood according to the Prague School's spectrum that ranges from "laws in the legal sense to simple rules of thumb." Sonesson examines the relationship between normalcy and normativity as it happens through time geography, visuality, embodiment of law, and cultural spaces of legality. These spaces can be permeable, have borders, be artifacts, respond to the gaze, constitute the umwelt, reflect intention or intuition, develop the spectacular function, and be rich with intention in the public sphere. Through the examples of the tick, the apple, dice, the boulevard, the cellphone, and the wearing of veils, the cultural parameters of spatiality challenge traditional notion of not only where we can find law, but the contested duet between private and public life. Audience and its reception play a vital role in the construction of rules and norms as they transpire and evolve in the semiotic construction of legal spaces. For Sonesson, the semiotics of space are performed and debated to understand their role in the public sphere in terms of behavior, expectations, and norms that reveal a lived notion of legality.

Wrestling with the semiotic construction of public space, Noah Viernes examines the visual economy in Bangkok as it fosters "an increasingly politicized visual culture." In his examination of public streets, Viernes considers the impact of the state on public memory and the ways that urbanity is presented through media in order to shape political activity and awareness in Thailand. Those who didn't experience the political upheaval of the 1970 or 1990s "are ordered into new fields of view and media instantaneity, a visual manifestation of neoliberalism that inhibits the possibility of a collective political consciousness." A constructed imaginary of community and purpose is created through the spatialized apparatus of governmentality in which the state controls the meaning and the remembering. Projected images are selectively managed for the purpose of ensuring the social order. In turn, state power, tourist spaces, and cultural representations operate to silence political discontent as "the magistrate, a master of norms, dilutes the reactive power of the political by pacifying, i.e. normalizing, its images." 
Rethinking the normalcy that considers the image not the mindset to be more deviant, John Brigham explores the new landscape of legality and obscenity in familiar, often innocent places, namely in public libraries and on the laptop. Brigham challenges the growing proclivity of enforcement frameworks that conflate danger, availability, and children with regard to sexually explicit images. The result is instead a focus on law that entraps and seduces, and where, "in the case of forbidden images that deal with sex, it had become the power of the law, perhaps more than the pornographer, that lurks menacingly just out of sight." He states "not seeing is what the law of forbidden images, of the obscene and the pornographic, is all about." By examining the role of the public librarian in regulating space in contrast with the privacy of one's laptop, Brigham considers the potentiality of available information and who is controlling the flow of this information in designated and non-designated spaces and why.

Information is often found through a variety of mediums that convey underlying meaning. In his work, Aaron Lorenz examines how society and law are shown through popular understandings of social justice captured through the use of humor in two American television sitcoms. In his analysis, Lorenz contemplates the topics of the shows in terms of how law works through negotiation, as these shows "represent that hazy area between what John Locke termed 'the state of nature' and what legal scholars call 'legal culture.'” Through comedic representations about banality and in conjunction with classical legal philosophy, approaches to societal rules contextualized through power, control, and justice are negotiated through humor, audience anticipation, democratic interaction. These rules act as social cues that are codified into social expectations and normative patterns for behavior in American society. Lorenz insightfully tells us that "to understand politics and law, we must understand what and how people say about it." The contextualization of popular understanding in this media outlet provides a legal space for understanding the rules and norms of living in American society that are nuanced, yet available enough to be an obvious source of legal knowledge that lurks in our conversations, our relationships, and our participation in the daily grind.

Challenging the contextualized understanding of what it means to be a professional athlete, Martin Hardie looks at the body of the professional cycler in accordance with the global anti-doping apparatus established by the World AntiDoping Code, with a focus on the Whereabouts System and the Biological Passport. Using a panopticonic approach to governmentality, Hardie articulates how power works in terms of surveillance, probabilities, and monitoring. These mechanisms of power examine the body as a source of deviance in need of regulation and control. While doping is not allowed, the medically-deduced probability of doping inside the body invites discipline as "what becomes punishable is an abnormality, in the cyclist's location, or their body, which suggests a probability that the invisible act of doping may have occurred" and "open up a new manner in which the invisible can be visualized." In this way, the body itself is a space under guard by exterior forces seemingly intent on repression and failure. The power to govern the body, accompanying mind, and arguably the soul, is mandated through expectation and the conjecture of likelihood, rather than truth, evidence, or even the allowance of possible doubt. 
Governing the body and its representation is the focus of the next article. Mark Brunger considers the image of local policing in the iconic, if not mythical, construction of the British bobby. In his work, Brunger considers the manipulated perception of public safety generated by the presence of the "visible police patrol." Through the 'bobby on the beat', the state is allowed, even welcomed, into social space, thus rendering these places more public and arguably, less localized. However, there's more to the bobby than just an attentive and legitimatized state presence; rather, the bobby represents British identity, insofar as the bobby mythologizes the narrative that "police officers in the UK really are "citizens in uniform"". While police, particularly local police are indeed members of the community, their position as directives of the state often take precedence over their sense of local sympathies. That job however, and the image of the British national identity, become one in the same in terms of the intended perceptions of a crimefighting public. Brunger writes "the problem with the active ownership of social space by police officers is that its make use of social labeling of certain parts of community" which already marginalized groups becoming "police property." Therefore, the symbolism of the local police is also the symbolism of governmentality in which if the bobby is construed as 'local', then those on the fringes are punished for existing outside the expected social order.

Governmentality operates spatially and semiotically in myriad contexts. Lucas Pizzolatto Konzen engages with the ways in which the tourist economy is managed by states in order to present sanitized impressions and routes for visitors. In his work in Acapulco, Konzen considers the framing of economic gain through images depicted on postcards and the construction of places to visit on state-sponsored maps presented to tourists. He states "tourism, now a globalized social phenomenon, is nothing but the process of consumption of space." This consumption involves a relationship between producer, consumer, and audience. The producer, or the Mexican government serves as the producer in generating perceptions of safety, authenticity, and historical valuation. The consumer, or tourist, in turn digests this prepackaging as a lived experience intended only for the visitor. The audience includes those subject to the former categorization without the benefit of inclusion. As a result of this relationship, Konzen describes two types of norms, legal and ideological, that are created and "of course subjected to social actors' interpretation." He discusses the 'tourist zone', or that area of the city that is tailored to a specific and intentional experience and omits much of public space that results in "normative expectations" about not only the tourist space, but the tourist and local experience as well.

Questioning the zones of economic prowess, Anne Wagner considers the ways in which our landscape is contaminated by visual noise, or commercial pollution in the forms of obtrusive billboards that arise on roadways, in traffic circles, on bus stops, on the sides of buildings, and throughout the urban environment. With the seemingly omnipresence of commercial messages, our natural environment and presumption of community are threatened to the degree that our sense of life is bombasted by constant commercially framing. Such visual clutter in the urban setting manipulates the visibility of what is seen and what can possibly be viewed in order to create an "environment for advertising companies [that] is like a 
playground where advertising signs colonize the natural environment to meet the needs of their clients." Wagner warns that such ubiquity in advertising placement in spaces that may otherwise be natural, unoccupied, or empty, assumes the power to redefine who we are as a community and what we want to see. Without a more critical engagement with what we see, we may one day become blinded by the colonizing view of our everyday. 